\title{
ANTUNES, Benedito; MOTTA, Sérgio Vicente (Org.). Machado de Assis e a critica internacional. São Paulo: Ed. Unesp, 2009. 279 p.
}

\author{
Marcos Rogério Cordeiro \\ Universidade Federal de Minas Gerais
}

\begin{abstract}
As editoras brasileiras estão devendo aos seus leitores uma lista comprida e importante de estudos já publicados no exterior a respeito daquele que é considerado nosso maior escritor, Machado de Assis. Para dar uma amostra pequena, mas significativa, basta lembrar os trabalhos de Anatole France (Machado de Assis et son oeuvre littéraire), John Hyde Schmitt (Machado de Assis and the modern brazilian short stories), Richard Graham (Machado de Assis: reflections on a brazilian master writer), Carlos Fuentes (Machado de la Mancha) e Dieter Woll (Die entwicklung seines erzählerischen werkes). Os trabalhos de John Gledson e Abel Barros Baptista já foram vertidos e publicados, assim como os de Paul Dixon (O chocalho de Brás Cubas) e Hellen Caldwell (O Otelo brasileiro de Machado de Assis: um estudo de Dom casmurro), um dos mais importantes, mas que nos chegou com quarenta anos de atraso. Desses últimos ainda faltam Machado de Assis: the brazilian master and his novels e Retired dreams: Dom casmurro, myth and modernity, de Caldwell e Dixon, respectivamente. Existem ainda exemplos de livros de estudiosos brasileiros, como José Raimundo Maia Neto (O ceticismo na
\end{abstract}


obra de Machado de Assis), que, por algum motivo particular, foram publicados no exterior antes de o serem no Brasil, e de livros de brasileiros que ainda não receberam uma edição nacional, como é o caso de The author as plagiarist: the case of Machado de Assis, organizado por João Cezar de Castro Rocha.

Esses exemplos, apesar de diferentes entre si, revelam o interesse da crítica estrangeira por nosso escritor e, consequentemente, por nossa cultura e nossa história. Por isso mesmo, a dívida das editoras é grande e o público leitor no Brasil fica descoberto com ela. Não me refiro apenas aos professores e pesquisadores da obra machadiana, que bem ou mal têm acesso a uma parte dessas publicações, mas principalmente aos alunos que ainda estão nos bancos da faculdade ou entraram há pouco na pós-graduação e que muitas vezes não possuem uma visão muito clara do quanto esse segmento é rico, tem qualidade e está bem adiantado. Muitos acreditam que tudo o que havia para se pesquisar sobre Machado, já foi pesquisado, analisado e interpretado exaustivamente pela crítica literária brasileira, e que a contribuição estrangeira serviria apenas para aferir um assunto já sabido. Para se ir além dessa limitação, é necessário ampliar a oferta de trabalhos que precisam ser traduzidos urgentemente. Uma divulgação maior ajudaria no contraste e na comparação entre o que se produz aqui e lá fora, podendo revelar - entre outras coisas - o uso diversificado do mesmo quadro teórico. Por exemplo, uma parte da crítica brasileira, de confessável inspiração bakhtiniana e pós-estruturalista, apresenta as "obras maduras" de Machado como exemplo de descoberta de uma metafísica da personalidade, que narradores e personagens já anunciariam como incertezas pós-modernas; por outro lado, Maria Luisa Nunes, que possui a mesma inspiração teórico-metodológica, defende em The craft of an absolute winner: characterization and narratology in the novels of Machado de Assis que há a continuidade entre as obras iniciais e as posteriores de Machado e que a complexidade da personalidade de seus narradores e personagens se deve a uma bem elaborada concepção dramática cultivada pelo autor. Todos sabemos que não é tão raro encontrar análises diferentes partindo do mesmo pressuposto teórico, mas o que surpreende neste exemplo é que a perspectiva crítica de Nunes, baseada em uma interpretação objetiva do texto, difira tanto - no método e na linguagem - daquelas que são praticadas no Brasil, dando a entender que ela se deixou levar mais pela curva de esclarecimento das obras e menos pelo prestígio de uma ou outra tendência teórica.

Para minorar um pouco a distância e o desconhecimento de nossa parte - pois, obviamente, os estudiosos estrangeiros procuram se instruir nas pesquisas dos brasileiros - foi publicado Machado de Assis e a crítica internacional, 
organizado por Benedito Antunes e Sérgio Vicente Motta. O livro é resultado de um simpósio ocorrido em agosto de 2008 na Universidade Estadual Paulista (UNESP), por ocasião das comemorações do centenário de morte de Machado, e contou com a colaboração de muitos pesquisadores estrangeiros. Lamentavelmente, nem todos os trabalhos apresentados vieram parar nas páginas dessa edição: faltaram os de Dain Borges, Jorge Edwards, Abel Barros Baptista, Victor K. Mendes, Hans Ulrich Gumbrecht, Sérgio Paulo Rouanet e Antonio Carlos Secchin. Mas nela se encontra uma boa seleção de temas e perspectivas: Jean-Michel Massa, por exemplo, explica como o interesse pelo teatro e a atuação regular na imprensa moldaram uma concepção de ficção em Machado e defende a importância da cultura e da literatura francesas em sua formação intelectual; Amina Di Munno analisa as influências da literatura e da música italianas em Machado; Daphne Patai deixa mais claros os meandros da lógica do mercado editorial nos Estados Unidos e como os escritores com prestígio intelectual, como Machado, se inserem nele; Thomas Sträter recupera passagens importantes da vida cultural brasileira - como a mudança de hábitos, quando os valores coloniais vão sendo substituídos pelos modernos, de feição burguesa e aristocrática - e mostra como Machado as representou; Todd Garth retoma a tradição filosófica de Schopenhauer - a construção de uma postura ética baseada no ceticismo, marcada pelo distanciamento e pela reflexão crítica para melhor analisar narradores e personagens machadianos, mostrando como o escritor brasileiro construiu uma linguagem que o afasta da representação realista e romântica; Paul Dixon procura por representações esotéricas em Memórias póstumas, demonstrando a presença de mitos e ritos xamânicos em certas passagens do romance, tornando-se mesmo um recurso que dá forma à narrativa.

Como se vê, trata-se de um livro com interesses particulares e assuntos sortidos. Ao todo são onze artigos de pesquisadores de instituições e países diferentes, incluindo dois brasileiros, Roberto Schwarz e Luiz Roncari, que encaminharam bem um tema que acaba por perpassar quase todos os trabalhos: o grau e o estatuto do universalismo machadiano e sua correlação com o nível e a função localista de sua obra. Trata-se de tema espinhoso, que rendeu debates acalorados no "simpósio" e que no livro pode ser recuperado com vantagens.

Todos os trabalhos partem do pressuposto de que a obra de Machado de Assis tem peso no cenário internacional e que contribui de modo decisivo para uma compreensão mais aberta e diversificada da cultura contemporânea. O problema é decidir sobre a voltagem da originalidade de nosso escritor. Para Massa, ela existe e é alta, mas depende da educação francesa de Machado, sem a qual 
não apareceria. A mesma opinião - embora exposta sem a mesma ênfase - é compartilhada por Amina Di Munno, referindo-se, por sua vez, à influência italiana, por Todd Garth com relação à alemã, por Kenneth D. Jackson com relação a uma influência mais geral, de inspiração filosófica além de literária, e também por Paul Dixon, que atribui a originalidade imaginativa do escritor brasileiro a uma certa tradição esotérica.

Ou seja, por trás do elogio universalista, que dá conta da atualidade de Machado, parece existir a busca genética desse universalismo. Esse dilema é tratado sem rebuços no artigo de Élide Valarini Oliver, no qual se lê uma explanação coerente e abalizada sobre os problemas conceituais em jogo. Segundo a autora, o modo como o repertório temático e formal da literatura mundial aparece na obra de Machado não corresponde exatamente à noção de "influência". Tal processo seria mais rico e mais complexo, nunca igual, posto que se modifica a cada instante, podendo aparecer não somente como "influência", mas também como "afinidade", "confluência", "deslocamentos" ou "distorções", mas sempre crivado pelo veneno da "ironia", recurso que garante a "liberdade da imaginação". Esse artigo esclarece melhor o debate, mas não o encerra. A intervenção de Luiz Roncari se mostra bastante oportuna quando insiste que não basta declarar que Machado dialoga com a tradição cultural estrangeira, nem mostrar onde ela aparece ou qual o seu teor; é preciso, afirma o crítico, procurar saber "como" isso ocorre e encontrar a lógica disso. Outro salto neste debate é dado por Roberto Schwarz, talvez o crítico que melhor tenha associado o próprio trabalho ao de Machado (é o mais citado nos artigos do livro). Ele parte de uma crônica sem maior repercussão ("O punhal de Martinha") para traçar as diretrizes do problema: ao comparar um fato ocorrido no interior da Bahia a uma passagem da História romana de Tito Lívio, Machado estaria pondo em evidência uma série de questões que levam a pensar os pressupostos tomados pela crítica, antes mencionados. Afinal, o narrador da crônica (cujos valores, postura e ideias se assemelham aos de outros narradores da ficção machadiana) se alinha com a ideologia cosmopolita em desagravo ao ambiente acanhado e provinciano do país; além disso, rebaixa os acontecimentos, os personagens e seus dramas (tudo contemporâneo e nacional) diante do exemplo de extração clássica e estrangeira. Ao mesmo tempo, a narrativa mostra que os fatos locais se sobrepõem aos universais e revela grandeza nos eventos comezinhos do interior e indignidade nos feitos gloriosos de Roma. Apropriando-se desse tipo de estruturação do problema, um achado do escritor brasileiro, Schwarz se volta então para o dilema mencionado. Sua hipótese, cuja inspiração materialista e 
dialética fundamenta, é a de que Machado - como, aliás, todo escritor com a mesma envergadura de gênio - não se deixa sucumbir diante das alternativas polarizadas (local ou universal), mas se eleva diante delas e as manipula de um jeito seu, evidenciando sua impropriedade e explorando as consequências: "Universalismo e localismo são ideologias ou chavões, ou timbres, de que Machado se vale como de pré-fabricados passíveis de uso satírico. (...) Por baixo da engrenagem retórica, lógica e estética do particular e do universal, pressionandoa e dando-lhe verdade, como um imenso subentendido, há luta de classes, luta entre nações, patamares desiguais de acumulação cultural, além de luta artística e crítica." (p. 29-31).

A publicação de um livro como esse traz muitas vantagens. Entre elas, devemos lembrar o fato - já apontado anteriormente - de termos em mãos uma pequena amostra do que é pesquisado pelo mundo afora sobre o maior escritor brasileiro e podermos comparar seus resultados com nossa própria visão sobre ele e sua obra; outra vantagem reside na oportunidade de pensar a literatura diante das premências do mundo contemporâneo. Não se trata aqui de defender patrioticamente as qualidades de Machado (que são muitas) como sinais de uma originalidade incomum, nem de cair na aceitação irrisória de um universalismo superior, mas de apanhar, em seu desenvolvimento dinâmico, as especificidades da combinação entre uma e outra coisa. A lição maior vem se for compreendido que o caso de Machado de Assis é um entre muitos. A tal combinação não se restringe a um ou outro escritor de prestígio internacional ou de fôlego universal, mas se mostra um problema para se pensar a literatura brasileira como um todo, um sistema de obras e autores postos em relação entre si e com o mundo. 